\title{
Tailored Blended Learning for Foundation Year Chemistry Students
}

\author{
Shannon Chamberlain, Daniel Elford, Simon J. Lancaster*, and Francesca Silve
}

\begin{abstract}
The chemistry foundation year at the University of East Anglia is a diverse cohort with a wide range of prior educational experience and confidence levels. A flexible learning program combining extensive online materials intended for asynchronous study and face to face peer instruction is provided. Study is divided into weekly topics. Students are directed to take a short introductory quiz at the beginning of the week, feedback on which allows them to tailor the extent of asynchronous learning to their own needs. All students attend a highly interactive synchronous teaching session which utilises active learning to develop their conceptual understanding. The week concludes with a reflective formative test. Measures of student activity on the online platform and audience response technology in the lecture theatre provide a quantitative picture of engagement with tailored blended learning, while semi-structured interviews provide qualitative insight into the student perception.
\end{abstract}

Keywords: Active learning · Blended · Just in time teaching · Peer instruction · Student directed

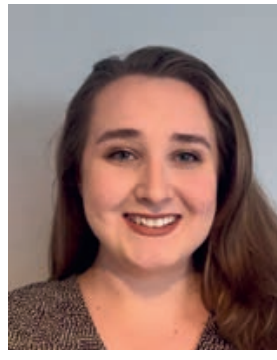

Shannon Chamberlain graduated from UEA with a first-class degree in Chemistry during the summer of 2020. Her final year research focused on gamification of the online resources for those studying the chemistry module during their foundation year. The research resonated personally with her since she previously studied the module during her own foundation year. Currently she is working towards becoming a primary school teacher, volunteering to help younger children catch up as a result of missed school time.

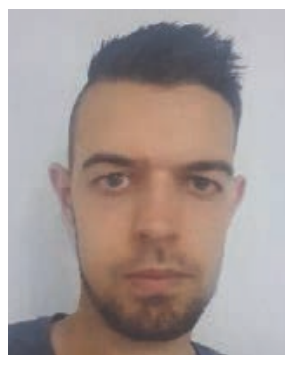

Daniel Elford graduated with a first-class honours degree in chemistry from Kingston University London in 2014 followed by four years in industry as a development chemist. He then completed a MSc in Information Technology at Anglia Ruskin University in 2018, spending a further year working in software development. Since 2019, he has been a PhD student in the School of Chemistry at the University of East Anglia. His pedagogical research interests include the integration of augmented and virtual reality technologies into chemistry education.

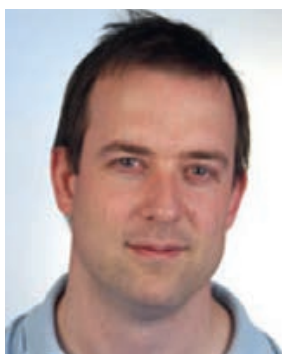

Simon J. Lancaster gained a $\mathrm{PhD}$ in Organometallic Chemistry from the University of East Anglia in 1996. He worked as Research Officer at the University of Leeds 1996-2000. Simon was appointed as Lecturer in the School of Chemistry at the University of East Anglia in 2000, Senior Lecturer in 2010 and Professor of Chemistry Education in 2014. He is the immediate past president of the Royal Society of Chemistry, Education Division Council and a UK National Teaching Fellow. Simon is course director for the University of East Anglia Chemistry with a Foundation Year degree program and convenes the Chemistry modules. His pedagogical research interests include active learning and augmented reality.

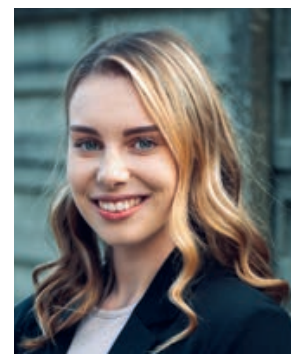

Francesca Silve obtained a BSc in Chemistry from the University of East Anglia in 2019 where she was awarded with the Katritzky prize and medal for best overall performance (at BSc). Since graduating, she has transitioned into a quantitative research role at Yonder Consulting (formerly Populus). During her final year of studies at UEA, Francesca completed a pedagogical research project focusing on the relationship between Science Foundation Year student's prior academic experience, their engagement with a blended learning approach and the impact on outcomes.

\section{Introduction}

The expression blended learning has come to the fore during the Covid-19 pandemic. ${ }^{[1]}$ Blended learning implies flexing a range of pedagogies across a course, choosing the most appropriate approach for the learning objective at hand. ${ }^{[2]}$ In the depths of a pandemic, that choice is curtailed, and more teaching is forced online, even when that might not have been the preferred means of delivery. Herein we describe a scalable blended delivery approach, developed before the pandemic. Foundation year chemistry students' self-direct aspects of their learning, tailoring it to their individual needs. We propose that the effort invested across the chemistry education community during the pandemic could be repurposed to deliver tailored blended learning in the post-Covid era.

\subsection{The Foundation Year}

Education qualifications in England are split into Levels 1-8 (Fig. 1). ${ }^{[3]}$ University Foundation Years were introduced to provide an alternative entry route to undergraduate degrees whereby the institution itself provides the student with their prior subject knowledge if they are lacking in sufficient pre-requisite qualifications (at level 3). ${ }^{[4]}$ The University and Colleges Admissions Service (UCAS) also refers to these programmes as a 'qualifying year' or 'year zero' as they lead to enrolment on year one of a traditional undergraduate degree if completed successfully. ${ }^{[5]}$ 


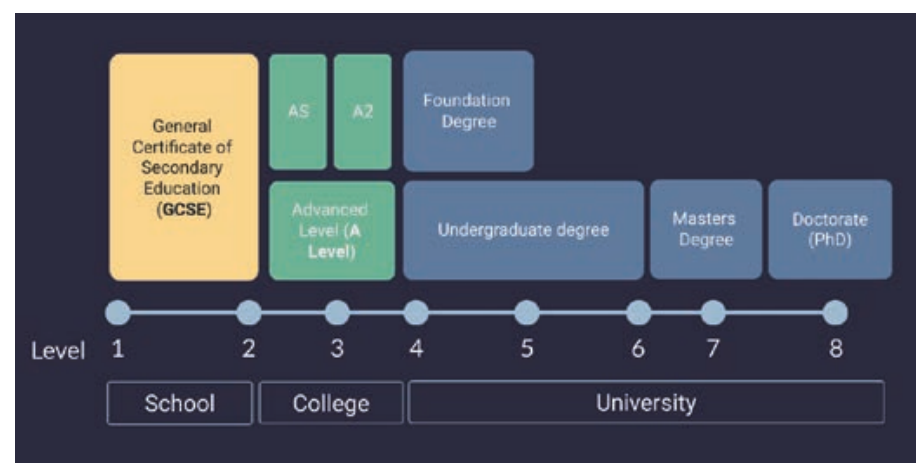

Fig. 1. Education qualification levels in England

The schools of Pharmacy, Biological Science, Environmental Science and Chemistry have Foundation Year programmes with a Chemistry module requirement. The foundation years were conceived to provide a non-traditional entry route to a University of East Anglia (UEA) degree. Applications are invited from mature students, those taking a new study direction, and students who have been disadvantaged during their secondary education. However, this route to higher education is becoming increasingly popular amongst sixth form graduates whose A Level grades were not sufficiently high, as Foundation Years usually have lower entry requirements. ${ }^{[6]}$ The contextual criteria applied to disadvantaged students differ between schools of study, and with the prevailing admissions climate, but can mean that students with $\mathrm{A}$ level grades $A^{*}-E$ in chemistry are admitted to our modules. Thus, the nature of the Foundation Year is such that the student cohort is comprised of 'groups of learners from different backgrounds with various degrees of prior subject knowledge, including none at all'.[7]

\subsubsection{A diverse cohort}

Since its inception, the Foundation Year cohort at UEA has not only increased in size but has shifted in demographic, presenting the academic staff with the challenge of engaging and facilitating the learning of students at both ends of the academic experience scale. ${ }^{[8]}$ The principal groups being the large number of students with A levels and prior Chemistry knowledge, for whom the course may be 'too easy' and repetitive, and those who have progressed through non-traditional academic paths, for whom the course content may be new or overwhelming. The Foundation Year course was designed to teach the pre-requisite chemical concepts that are presented at A Level so as to allow those who do not have this qualification to proceed with equal prospects to those who do. However, since many students on the Foundation Year have completed A level Chemistry, most of the learners have supposedly already been taught this material whilst the remainder of students are learning the content for the first time. ${ }^{[9]}$

\subsection{Flipped Teaching}

To overcome these challenges, we have tailored the learning experience to the diverse students on the course by redesigning the teaching style - taking influence from flipped teaching and active learning approaches. In essence, flipped teaching seeks to move the transmission of information out of the classroom, freeing contact time for constructive development of understanding and application through active learning. Flipped teaching is a concept, not a recipe and there are many modes of implementation. These models generally consist of providing a pre-lecture video or screencast, often complemented with a multiple-choice quiz, in-lecture interactive techniques such as learner response systems and discussion, and a post-lecture activity. Assigned reading is a common alternative. Where preparation for face-to-face is coupled with interactive web resources, Just-in-Time-Teaching aims to ensure the contact sessions reflect the needs of the students. ${ }^{[10]}$ The successful outcomes as a result of the implementation of such models in large introductory classes in higher education are well documented. ${ }^{[1,12]}$ Seery has comprehensively reviewed flipped teaching in chemistry higher education and charted its evolution from teacher's intuition to an evidence-supported practice set within a theoretical framework of cognitive load theory and self-determination. ${ }^{[13]}$

Eichler \& Peeples carried out a comparison of the effects of 'flipped' and 'non-flipped' approaches to teaching general Chemistry courses. Evaluation of the results found that the convenient access to learning resources and increased active learning in lectures, as a result of the 'flipped' model, led to 'significant improvement in the course grade point average'. ${ }^{[14]}$ The researchers also recognised the flexibility that a flipped approach, which incorporates pre-lecture video resources, can provide. They stated that "the students are able to view the videos and work with the interactive tutorials at their own pace and if necessary multiple times, allowing the students to tailor the learning experience to their own needs", anticipating the approach we outline herein. ${ }^{[14]}$

We have been recording lectures at UEA since 2007 and, like others, find the practice is popular with students. ${ }^{[15]}$ We had concerns about the uses to which our students were putting these recordings, particularly binge-watching in the run-up to examinations. In response, we developed interactive video highlights, which we termed Chemistry Vignettes. ${ }^{[16]}$ Larger scale studies have shown a fascinating discipline-dependence upon patterns of recording viewing, with chemistry students less likely than mathematics students to view recordings as a means of consolidating understanding after lectures. ${ }^{[17]}$ There is no compelling evidence that provision of recorded lectures discourages attendance, nor that it improves learning outcomes. If lecture recording is to have a positive impact on higher education, it will be through teaching design that facilitates active learning. ${ }^{18]}$

Kinsella \& Lillis conducted a study in which they employed an audio-visual 'screencast' as a pre-lecture resource to assess the impact on learner engagement.[7] The videos were no longer than 6 minutes and were complemented by a multiple-choice quiz and served as preparation for the week's lecture. The study found that students did not use the resources prior to the relevant lecture as expected, but instead returned to the resources at different points in the module, especially leading up to assessment. They also concluded that students should decide for themselves if lecture capture viewing is useful for them and advised that if they wish to do so, students should view the videos promptly around the time of the lecture to benefit the most.

Research by Allan involved comparing fully flipped, partially flipped and non-flipped approaches to teaching Foundation Year Chemistry students to assess the impact on learner understanding and attainment. ${ }^{[4]}$ The fully flipped model included pre-lecture material consisting of a Moodle lesson or a fully animated PowerPoint presentation, including worked examples, as well as interactive problem-solving activities and group work during classes. The researcher concluded that whilst it was clear that "engagement is crucial for learners to achieve their potential", the fully flipped model can improve learner attainment but the effectiveness of this approach is dependent on the complexity of the subject area taught.

A potential limitation with flipped teaching is that it requires the students to take responsibility for their learning experience. ${ }^{[11,19]}$ The literature suggests that simply encouraging students to voluntarily participate in activities and engage with material is insufficient and that students are reluctant to do so unless it is enforced.

In essence, unless participation with the learning activities is compulsory or summative, students are less likely to engage, irrespective of whether it is beneficial to their academic outcome. 
Burnstein \& Lederman found when the use of clickers accounted for a significant proportion of their module grade, increased attendance, alertness in lectures and preparation for quizzes were among the positive outcomes. ${ }^{[20]}$ It is necessary to consider that the extent to which students engage in an activity is affected by the way they perceive and value the resource. Struyven et al. highlighted that, as a result, the learning may differ from that intended by the lecturer.[21]

\subsection{Active Learning}

We subscribe to the definition of active learning as any pedagogy that seeks to put learners in control of constructing their knowledge rather than depending upon them passively absorbing it. ${ }^{[22]}$ Most studies of active learning pedagogies have focussed on demonstrating effectiveness against conventional measures such as assessment results. ${ }^{[23]}$ The actual interactions of active learning tend to be regarded from a socio-constructivist perspective.[24] Constructivism is a theory of learning founded on the premise that students build on their existing abilities. ${ }^{[25]}$ We have found the notion of a zone of proximal development, where students can achieve and benefit more from interaction with a (more knowledgeable) peer, very helpful in guiding our practice. ${ }^{[26]}$ Adherence to this model ensured that we posed challenging questions in what is described below as the sweet spot, that divided our students and collectively challenged them, rather than succumbing to the temptation to pose straightforward questions that simply reviewed their existing knowledge.

\subsubsection{Peer Instruction}

Peer instruction was developed in the late 1980s and early 1990s for Physics education at Harvard by Eric Mazur. ${ }^{[27,28]} \mathrm{He}$ was responding to the familiar sense of frustration felt when observing that students are simply not grasping the underlying concepts. Mazur initially used the term peer instruction just to describe the interaction between neighbouring students. His methodology was to give a short presentation on a key point and to immediately follow that with a ConcepTest in the form of multiple-choice questions as shown in Fig. 2.

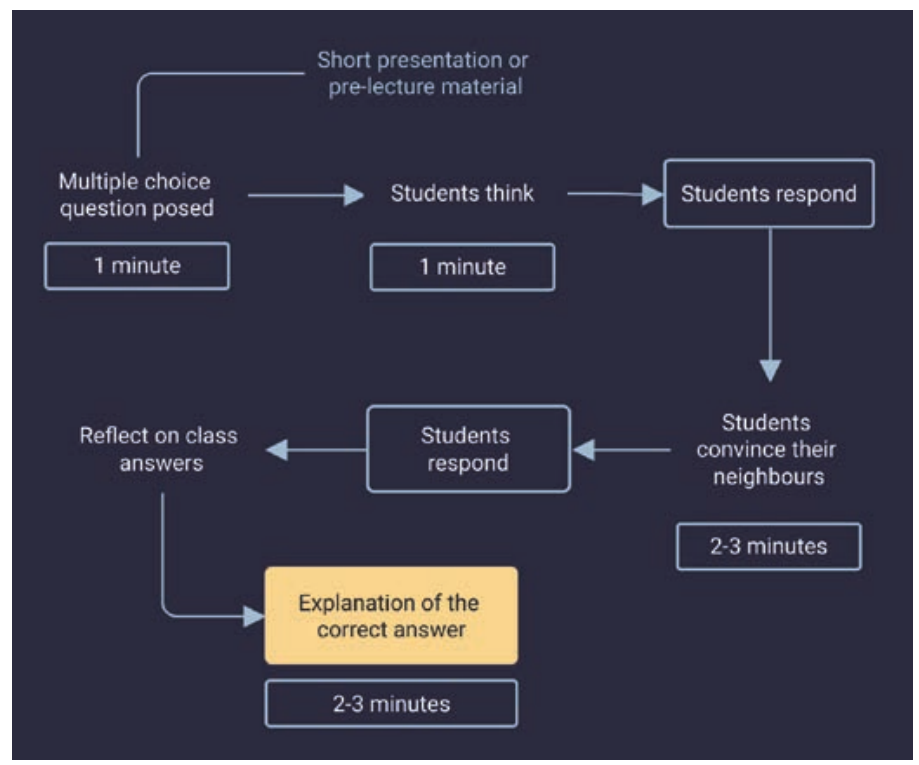

Fig. 2. Mazur's ConcepTest, the practice of peer instruction (with reference to the list by Mazur, 1997).

In active learning, how one proceeds is always dictated by the behaviour of the students and there is a suggested pattern of response in peer instruction (Fig. 3). ${ }^{[29]}$ It is the relative flexibility

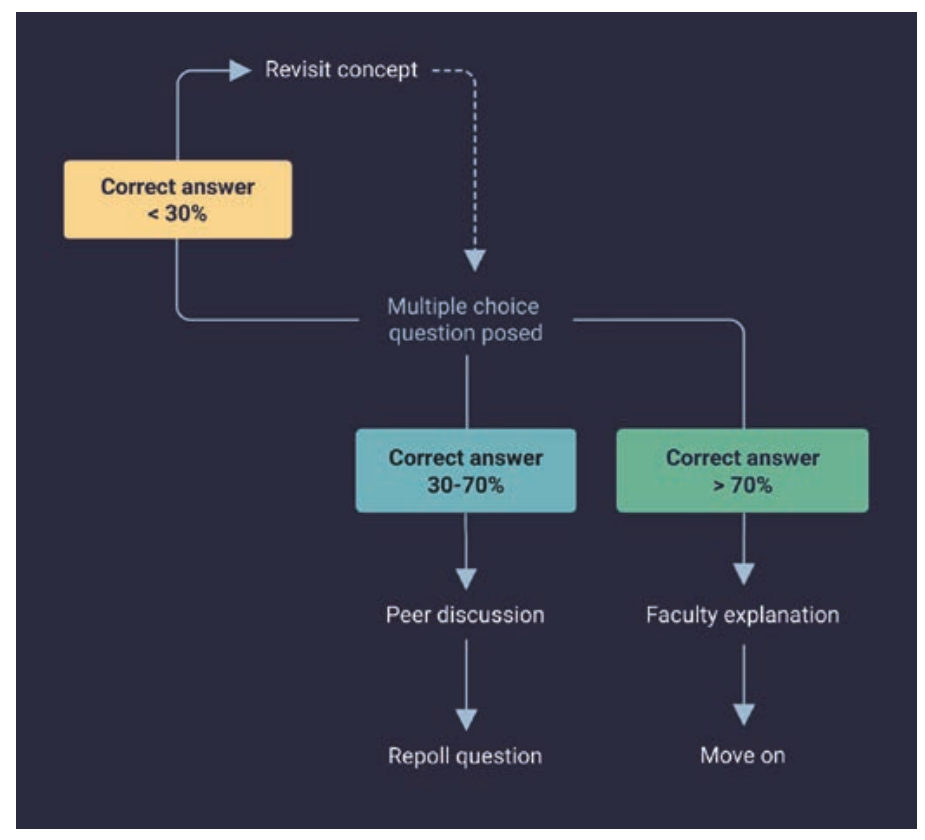

Fig. 3. Responding to the student answer distribution (with reference to Lasry et al., ref. [29]).

of peer instruction amongst active learning pedagogies that has proven so attractive. ${ }^{[30]}$ Ideally, after the initial student response, there will be a spread of answers. If every student was correct initially, there would be no opportunity for learning and nothing productive to be gained by a discussion. Indeed, that students have been drawn to the distractors confirms that the distractors reflect common misconceptions and present them for discussion. If conversely, there were very few correct answers, this would suggest there would be too few students with the correct conceptual understanding to carry the argument during a discussion between students. If that happens the faculty member would normally seek to explain the concept afresh. This effective range of student responses was termed the 'sweet spot' by Mazur.[27] The boundaries are a little arbitrary, but the sweet spot will be approximately $30-70 \%$ with the correct answer for a typical four option multiple choice question.

\subsection{Establishing Parameters of Student Engagement}

As well as allowing a more flexible approach to teaching a large and diverse cohort, the flipped teaching approach aims to promote, encourage and increase student engagement in academic activities. Student engagement is a key concept in establishing successful outcomes for students themselves as well as the institution. ${ }^{[31,32]}$ Promoting student engagement is of particular importance to a cohort such as a Foundation Year, in which a proportion of academically underprepared learners are present.

This study aims to examine the extent and patterns of engagement throughout a Foundation Year module. Student engagement is a multifaceted concept. Coates stated that "student engagement is based on the constructivist assumption that learning is influenced by how an individual participates in educationally purposeful activities". ${ }^{[33]}$ While this is still considered at the heart of engagement, many authors have also identified the emotional, behavioural and cognitive components that comprise the experience. ${ }^{[33-35]}$ The behavioural component refers to 'observable behaviours' such as attendance and participation, whilst the emotional component refers to learners' feelings surrounding their learning experience including boredom or interest. ${ }^{[36]}$ Cognitive engagement refers to strategic or self-regulated learning that leads to effective understanding of material taught. [37]

Regardless of the debate surrounding the expression, the importance of student engagement is well recognised. Sunday con- 
ducted a correlation study in which they investigated task engagement in relation to learning outcomes of 60 science students. They found a significant positive correlation between student's task engagement and academic achievement in Chemistry. ${ }^{[38]}$ Similarly, Singh, Granville, \& Dika examined the effects of motivation, attitude, and academic engagement on student's achievement in maths and science. Their results included evidence of the effects of engagement in academic work for success in these subjects. [39]

In addition to establishing the value of student engagement, routinely assessing student engagement is of equal importance in directing teaching strategies. ${ }^{[40]}$

Student engagement is a shared responsibility between the students, the institution and educators. ${ }^{[41]}$ As highlighted by Coates, Krause \& Coates and Yorke, it is the relationship between student's motivation and interactions and institutional commitment to providing appropriate resources, learning opportunities and pedagogies with which they can interact. ${ }^{[31,42,43]}$

The implementation of a blended teaching approach enforces the educator's responsibility to foster student engagement, as this pedagogy ensures the introduction of learning resources such as multiple-choice quizzes, videos and discussions (facilitated by audience responses) that are not usually provided as part of traditional Higher Education teaching. Despite the availability of such resources, it is the student's responsibility to engage with them. ${ }^{[30]}$

A student's engagement with academic activities, however, is often dependent on their circumstances, backgrounds and non-institutional influences. ${ }^{[44]}$ Some of these factors may not provide consistent adverse effects on engagement but may impact significantly during times of crisis. ${ }^{[45]}$

For the purposes of this research, student engagement is defined as 'the process by which students invest time and effort into completing, participating in or interacting with the learning resources available to them'. The behavioural component of student engagement will therefore be measured, using 'learner analytics' and administrative records as sources of quantitative observable indicators of engagement. This is complemented by qualitative interviews that will therefore aim to provide an insight into the emotional component of engagement.

\subsection{Research Questions}

The following research questions are posed:

1. Is the tailored blended learning approach effective in engaging a large and academically diverse student cohort?

2. What are students' perceptions of the teaching style and does this affect their academic engagement?

\section{Approach}

The number of students enrolled on the 'Introductory Chemistry' module, a first-semester module of the UEA chemistry Foundation Year, increased between the 2016/2017 (131 students) and 2019/2020 (280 students) academic years. The aspect of prior knowledge analysed in this study can be simplified into whether enrolled students previously achieved an A Level qualification in Chemistry (Fig. 4). In addition to the significant increase in enrolled students, the percentage of students completing this module, already possessing an A Level Chemistry qualification, also increased between the 2016/2017 and 2019/2020 academic years.

\subsection{Experimental Design and Participants}

Although the implementation of a new teaching approach is the prerogative of the module organizer and teaching team, the evaluative aspect of the investigation introduced ethical considerations. The ethical dimension contributed to a wider attempt to engage the students in a discussion about why we were teaching in this fashion. We presented the evidence for the effectiveness of active learning to our students. In practice, no students

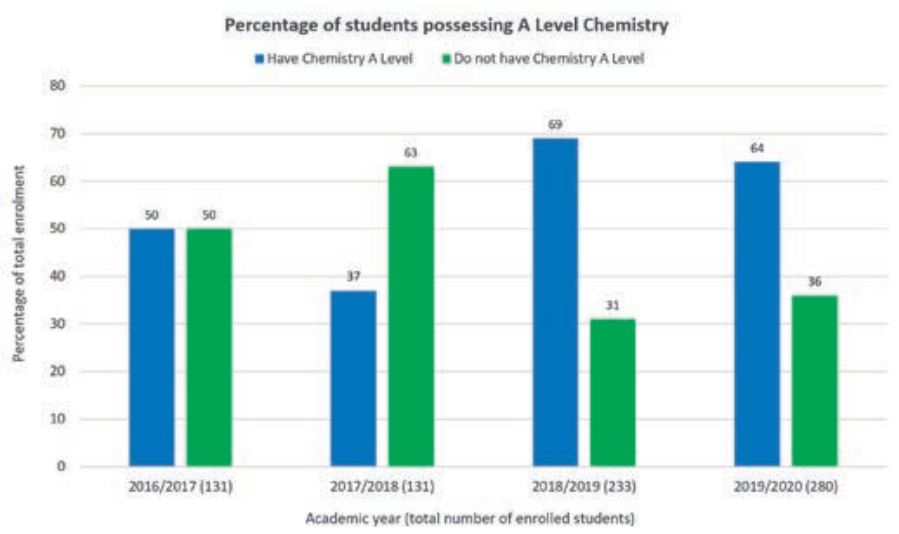

Fig. 4. Percentage of enrolled students on module 'Introductory Chemistry' who previously completed an A Level qualification in Chemistry.

questioned the approach until the module evaluation stage. All student anonymization and data protection processes employed during this study agreed with the ethics regulations detailed in the application. Data examined was from students enrolled on the 'Introductory Chemistry' module, between the 2016/2017 and 2019/2020 academic years.

\subsection{Teaching Pattern}

The Foundation Year was divided into weekly topics and a consistent scaffold of both synchronous and asynchronous teaching activities presented. The teaching pattern is summarised in Fig. 5. This approach was presented to the students on the module at an introductory lecture in the first teaching week. The students were verbally encouraged to utilise and engage with the resources available, whilst making it clear that any scores from the quizzes or tests did not directly count towards their module grade. Thus, engagement with the teaching resources was largely voluntary and the assessment formative.

At the beginning of each topic, prior to any timetabled teaching sessions, the students were asked to complete a short introductory quiz on the Blackboard virtual learning environment. The purpose of the introductory quiz was to allow the students to gauge their own understanding of the week's teaching material. If the student scored highly and felt confident in their understanding, then they were instructed to proceed straight to the teaching session. However, if the student scored poorly, they were advised to view a video in advance of the teaching session to provide an initial introduction and reduce the cognitive load in the live session (pre-lecture material). The videos consisted of a screencast recording of the lecture delivered on the module in the previous academic year and have been edited to approximately 35 minutes in length. The teaching session (of which attendance was compulsory) consisted of peer instruction. ${ }^{[46]}$

\subsubsection{Peer Instruction Questions}

The question being posed should require students to understand or apply the concept and not simply to recall the correct answer. Furthermore, we aim to set the question in Mazur's 'sweet spot'; not too easy and not too hard.

The practice of peer instruction is such, that if the instructor succeeds in pitching the question in the 'sweet spot' for the cohort, each question may consume up to ten minutes of class time. Given that the nominal 1-hour slot equates to 50 minutes of teaching time, we prepared anything up to 10 peer instruction questions. If the question is too easy then it takes up very little time. If too hard, the peer instruction methodology suggests that the instructor will provide some guidance (Fig. 3). Rarely, due to 

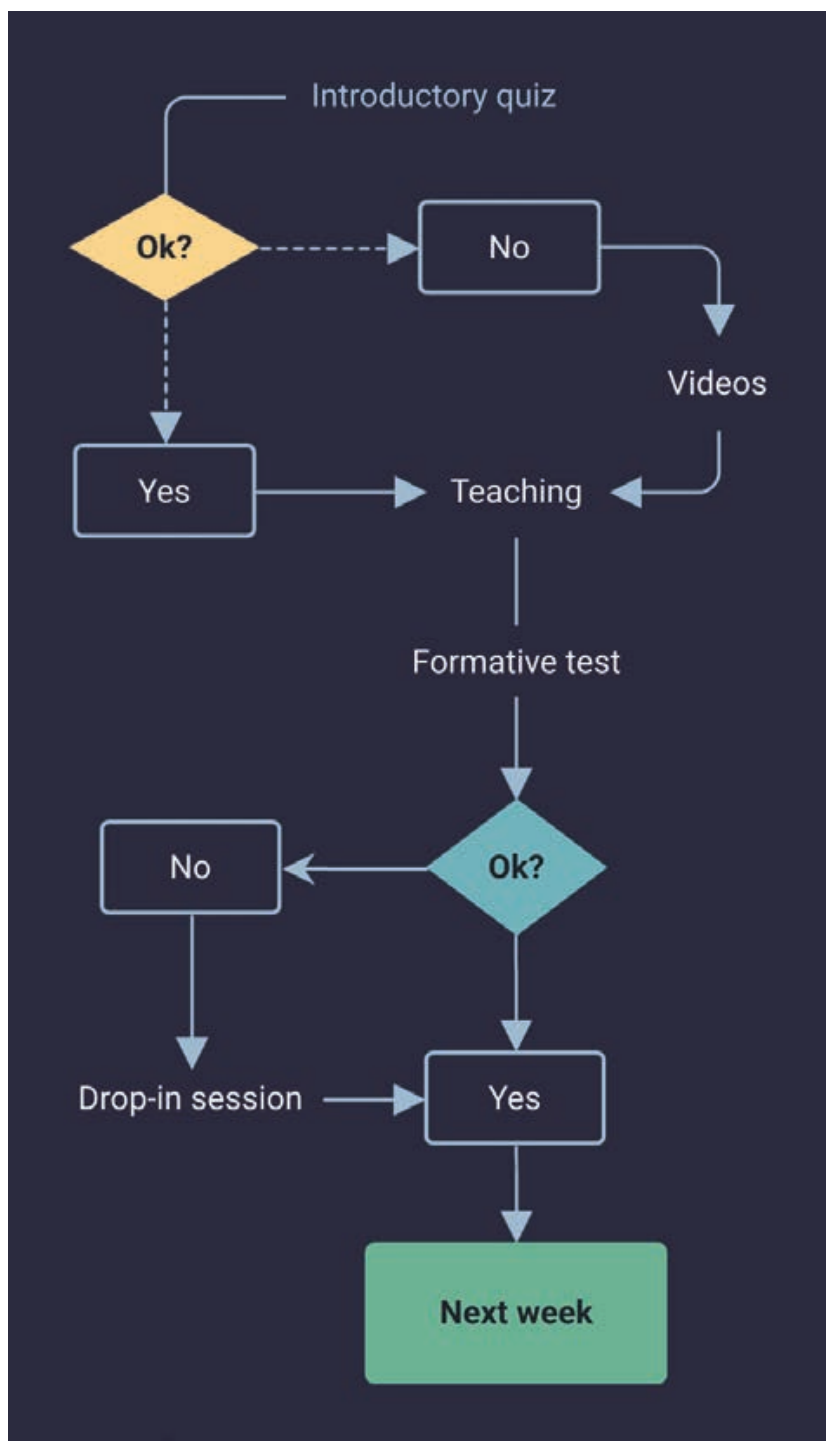

Fig. 5. Instructions to students on how to direct their own learning.

time constraints, we will concede that we have included a concept too many for the teaching session. If deemed crucial to the course, we will return to it at the next session. The awareness that active learning brings means occasionally having to acknowledge that the class have failed to grasp an idea.

After the teaching session, the students were encouraged to complete a formative quiz on Blackboard to determine the extent of their progress and assess their understanding. Drop-in sessions were then available to students who scored poorly in the test or required more support - attendance at these sessions was voluntary and was not formally recorded.

\subsubsection{Quantitative Approach}

Attendance at timetabled teaching sessions is routinely recorded as part of University procedure. Data was also collected from the digital audience response system used during peer instruction. We use the system in an anonymous fashion and therefore only record the total number of student responses to a multiple-choice question, without any profiling. The remaining quantitative data was generated from student's engagement with the Blackboard VLE resources (quizzes and formative tests).

\subsubsection{Qualitative Approach - Interviews}

Qualitative interviews were carried out to gain an insight into the quality of, and reasoning behind, engagement with learning resources as well as student's perceptions of the teaching style.
Students were invited to participate in a one-to-one interview about their prior academic experience, attitude towards the Foundation Year and their engagement with the module. The interviews were carried out in a semi-structured style to yield longer, more indepth responses.

\subsubsection{Qualitative Approach - Mid Module Feedback}

As part of the routine evaluation of the module, students in the 2017-18 academic year were invited to anonymously complete a 'mid-module evaluation slip' during week 6 of semester one. This gave the students the opportunity to provide feedback directly to the lecturer/module organiser, with a view to informing changes for the remaining weeks of the module. Unlike the interviews, where multiple questions were posed to generate responses, these evaluation slips allowed the students to express one or two main statements regarding any aspect of the module which they felt most passionately about. These therefore often represented the students' main concerns, satisfactions, or areas for improvement of the module.

\section{Results}

\subsection{Quantitative Results}

Prior to exploration of the data collected, information regarding students who had opted out of the study at any point throughout the semester was removed. Over the course of the semester (from week 2 to week 11) an exponential decrease in Blackboard engagement is observed. The increase in engagement during week 9 of academic year 2018/2019 was the result of a targeted teaching research intervention taking place; students were particularly encouraged to complete this resource.

Student attendance data allowed for the normalization of audience responses. We report the highest number of responses to a 'one response only' multiple choice question each academic week. In this instance, the indicator of engagement is being captured in a lecture theatre as opposed to an online learning platform such as Blackboard. Here too a general decline in engagement is recorded (Fig. 6). ${ }^{[47]}$

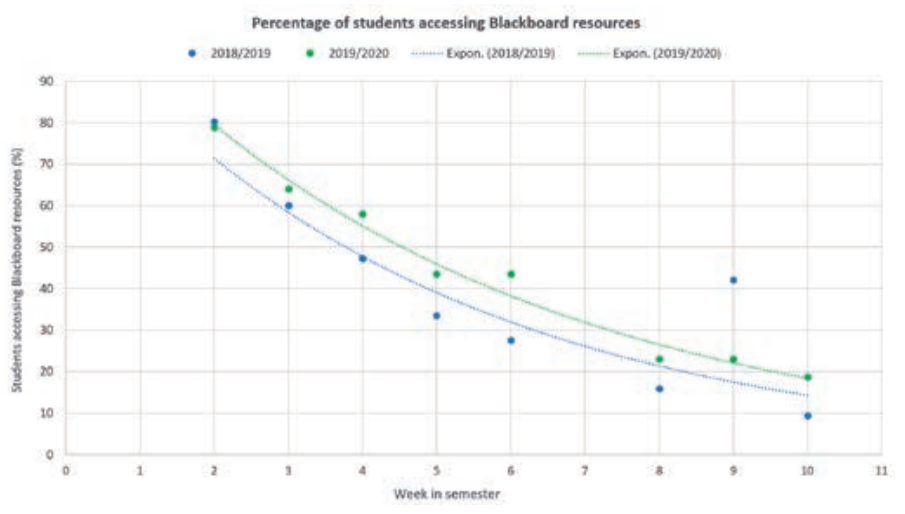

Fig. 6. The total number of Blackboard accesses made by students each week throughout semester one.

Clearly many students disengaged with the asynchronous component of the pedagogy throughout the semester. It is possible that some students replaced the Blackboard resources provided to them on the module with alternative external resources and that the trend seen in Fig. 7 does not exclusively represent a decline in learning effort, but instead represents a shift. Responses from the interview analysis supports this:

"I was finding a different video on YouTube and watching someone else explain it like Khan Academy or Crash Course." 
"I would have my head in a book rather than going through things on the internet and sort of seem to learn better if I've got a physical book in front of me."

"It was much easier for me to use my A Level textbook instead of [the online resources] to explain."

Given that students' 'in-lecture' engagement experienced a significant decline, it is tempting to speculate that most students who stopped accessing the Blackboard resources provided on the module, stopped using weekly resources (including alternative resources) all together.

This data also suggests that student's willingness to participate is dependent on the consequence associated with not participating. Attendance, although it does not contribute directly to the student's module grade, is compulsory and routinely monitored. Insufficient attendance might ultimately result in disciplinary action from the university and thus, attendance remains relatively consistent throughout the semester. However, as much as engaging with resources should benefit the student's learning outcomes, it does not contribute towards their module grade and, whilst it is encouraged, it is not routinely monitored and there is no disciplinary consequence to not fully engaging, and it is tempting to speculate that this contributes to the trends observed in Figs 6 and 7. As discussed by Burnstein \& Lederman, students are more likely to be engaged when completing an activity that contributes to their module grade. ${ }^{[20]}$ The somewhat unpalatable implication is that since the learning resources employed on this module are completely formative, students were less likely to

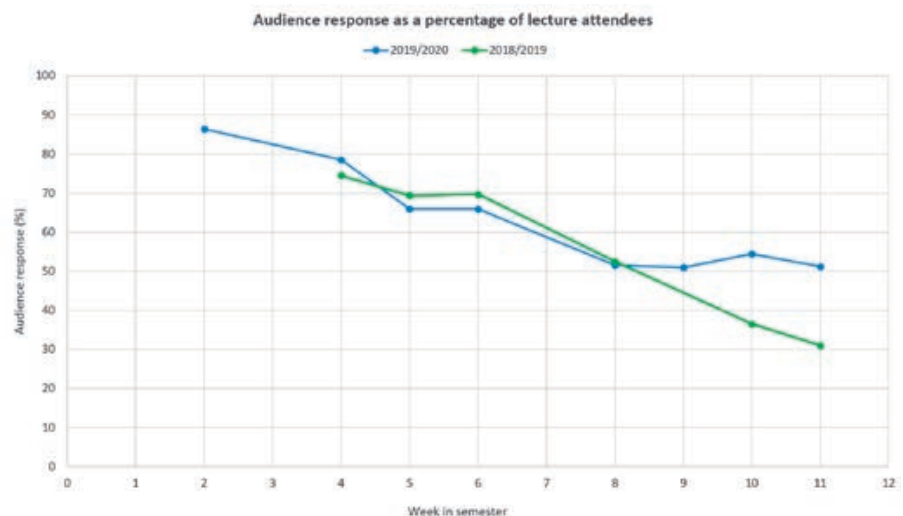

Fig. 7. Audience response as a percentage of lecture attendees throughout semester one.

\section{interact with them}

\subsection{Qualitative - Mid Module feedback}

The main themes which emerged from analysis and coding of the response slips are summarised in Table 1.

In many of the response slips, the students expressed the need for more explanation of concepts in the lectures as well as the want for more resources to be made available to them. The excerpts below are among those taken directly from the response slips.

"Explain the answers of the questions in more detail."

"More resources provided for extra reading to help with teaching/lectures."

From observing the declining trend in Blackboard resource access throughout the module (Fig. 6), it is somewhat surprising that many of the students wanted more resources considering that they were not consistently utilising the resources already provided.

Nevertheless, in numerous responses, students expressed satisfaction with the teaching style with many students highlighting a particular resource or aspect of the style that they particularly enjoyed.
Table 1. Main themes arising from analysis of mid-module evaluation responses and their frequency.

\section{Main theme}

Response frequency

Provide more resources/

explanations

I like the teaching style/

a particular resource

Clarify what I need to know for the exam

The content is easy/too easy

Flipped Teaching -

negative comment

Additional support needed/ struggling

Miscellaneous/specific Chemistry problem

A Level - negative comment

No A Level -

negative comment

The content is hard/

too hard

Separate A Level/

no A Level groups or work

A Level - positive comment

No A Level -

positive comment

"I am enjoying the lectures and teaching style."

"The Turning Point [audience reponse] questions are helpful in lectures."

"Really like the structure of the module and [the lecturer's] teaching style."

In some of the most reflective comments, the students referred to their A Level or lack of A Level knowledge and how that affects their perception of and experience on the module.

"I am finding it difficult to keep up with the lectures on Blackboard and so get confused in the actual lectures because I don't have the A Level knowledge."

"Some lectures you jump right into the topic and don't thoroughly go through some parts which confuses some who didn't take A Level Chemistry."

"Only criticism is that it is not difficult enough for those who have done A Level Chemistry. If the lectures are compulsory (as they are for me) then they really aren't relevant or necessary."

"Can be tedious as only going over AS content."

"Ifeel that at the moment I am only refreshing my knowledge from A Levels and haven't learnt anything new yet. However, the lectures are still entertaining. Ifeel like it's hard to revise outside of lectures when I already know the content."

The students are aware of the problems and challenges encountered in teaching a large and academically diverse cohort. They indicate that whilst a flipped teaching approach is enjoyed by some, many students feel it may be unsuitable for the cohort as a whole and that splitting the students into sets based on their academic ability and adjusting the teaching style accordingly may be necessary. 


\subsection{Interviews}

The interviews provided an opportunity to obtain more indepth responses from the students' reflection of the module to gain better insight on points raised during the mid-module feedback exercise.

The initial interview questions were used to identify the participant's academic backgrounds to contextualise their responses. The 14 participants consisted of 5 females and 9 males, Among the 14 participants, 8 had achieved an A Level in Chemistry prior to commencing the Foundation Year.

Of the participants, 8 had not taken any time out of education before commencing the Foundation Year whilst 6 participants had taken time out of education. The participants were asked if they had applied directly onto the Foundation Year or if it had been offered to them by the University. Eight of the participants revealed that they were offered their Foundation Year place rather than applying for it on their own accord whilst the remaining 6 participants had applied for the Foundation Year directly.

During the interview analysis, four main reoccurring themes emerged. These themes were categorised into two topic areas: those relating to the Foundation Year (confidence) and those relating specifically to student's experiences on the Introductory Chemistry module (academic diversity, extent of prior knowledge and experiences, and proactive in learning).

\subsubsection{Extent of Prior Knowledge and Experiences}

Like the mid-module feedback, the students regularly referred to: (i) their A Level, (ii) lack of A Level knowledge or (iii) their previous educational or life experiences. This theme often emerged when the students were speaking about their use of the learning resources provided on the module.

“...it was very much AS Chemistry, so I didn't need as much support, I already had a good grasp of all the topics." (Participant 8)

"...Introductory Chemistry is all the foundation stuff which I'd previously learnt in AS Chemistry therefore after doing A2 Chemistry I felt like I didn't need to go over the basics... ....as I realised 'actually I can do this', I stopped engaging..." (Participant 1)

"I didn't use any of the videos because I thought they were long and tedious. One hour for things I [already] knew." (Participant 7)

As anticipated, some of the participants, particularly those who had A level Chemistry (participants 1 and 7), indicated that they stopped using the resources as they already knew the material. Participant 2 relates their lack of educational experience and time taken out of education to their frustration with the teaching style whilst participant 4 reveals that they did not use the quiz resources due to their lack of prior knowledge.

"I think going from GCSE and not doing anything for years and then going to Foundation Year it's hard anyway but then if you hadn't watched the videos or had a chance to look at the slides [it's harder] because [the lecturer would] just skip through all of them to get to the next Turning Point question." (Participant 2)

"In all honesty I didn't do the quizzes because I really didn't

know half of the answers." (Participant 4)

Some of the other students who had taken time out of education brought up age and maturity when speaking about their engagement on the module.

"I've been in the world of work and I know what it's like to not have anything that you're working towards so not that I'm actually here, I grab it with both hands. I notice it a lot, the life experience I picked up having that big gap in education not a lot of the other students seem to have that so they think they can breeze through it all..." (Participant 9)

“I think some people don't answer the [Turning Point ques- tions] but that might be an age thing. When I went to University the first time, I would never ask any questions and never interact with anything in case I asked a stupid question but when you grow older you realise there's no such thing, all questions are valid." (Participant 6)

Participants 6 and 9 communicated that their life experiences had a positive effect on their attitude toward interacting and engaging with the module. Participant 6 indicated that their maturity relative to the other students on the course had resulted in increased confidence. Participant 9 indicated that their previous life experiences have acted as motivation in their commitment to attain a degree, as discussed by Bye, Pushkar \& Conway. ${ }^{[48]}$

\subsubsection{Proactive in Learning}

The student's responsibility to learn is identified as an important aspect of student engagement and as one of the main concerns associated with a flipped teaching approach as lack of engagement will not lead to effective learning. ${ }^{[4]}$ Some of the students in this study highlighted their responsibility to engage and their self-determination when reflecting on their attitude towards learning on the Introductory Chemistry module.

"[The lecturer] sort of just guided you in what you needed to know, and it was up to you to go and learn." (Participant 3)

“...obviously, it's about how much self-study and stuff you're willing to put in...[the teaching style] is as good as it kind of can be it's just more people need to engage with it...it's like anything, the lecturer can only do so much... if you don't log onto Blackboard and do any of [the resources] then there's no point to it but, it does work if you're responsible for your learning." (Participant 6)

"I'm quite determined to do as best as I can this year because I want to get onto the Masters." (Participant 9)

"I'd always answer [Turning Point questions], I'm the kind of student to do that." (Participant 8)

\subsubsection{Confidence}

Participants 3, 7 and 10 all spoke about 'deciding' to do the Foundation Year, thus revealing that they had a choice in this matter. Participant 5 refers to the concept of self-confidence, opining that they would not be as confident without the Foundation Year. Other students also reported feeling increased confidence as a result of being on the Foundation Year.

"...I've been able to gain more confidence with all of my academics and move forward in a much healthier way." (Participant 8)

"I'm a lot more confident now that I'm halfway through the Foundation Year than I was at the start. I've realised that I'm not as bad at Chemistry as I might have first thought I was." (Participant 9)

"I think my confidence in Chemistry has improved." (Participant 5) "I think I'll be as ready as I'll ever be [to start first year] and that purely because of the Foundation Year, especially my Chemistry confidence has improved a lot." (Participant 6)

Participants 5, 6 and 9 all reflect on experiencing increased confidence in Chemistry specifically. Participant 9 indicated that their own perception of their Chemistry ability has changed as their confidence increased. Ellis and Allan present anecdotal evidence to suggest that Foundation Year students are better prepared for first year of University than their peers enrolling directly onto first year. ${ }^{[49]}$

In addition to the emergent themes discussed above, the student's responses also allowed for their reasons for engaging/ not engaging and their perceptions of the teaching style to be observed (Table 2). The frequency of each point raised below is included as they do not necessarily represent common or reoccurring opinions amongst the participants but does demonstrate that there are multiple reasons to engage or not engage and that they are somewhat unique to an individual. 
Table 2. Students' perceptions to the teaching style based on participant interview responses

\begin{tabular}{|l|l|l|l}
\hline Main theme & \multicolumn{2}{|c}{ Reason (frequency) } \\
\hline Lack of engagement & Build-up of other work (1) & Resources not engaging/suitable (3) \\
\hline & Existing A Level knowledge (6) & Struggling to keep up (3) \\
\hline Lack of organisation/forgetting (1) & Technology problems (6) \\
\hline Lack of time/other commitments (1) & Too academically diverse (6) \\
\hline Octive engagement & Opinions of the lecturer (4) & Using external resources instead (3) \\
\hline Personal issues (1) & Was not enforced (2) \\
\hline Age and maturity (2) & Interest in the subject (2) \\
\hline Engagement made easy (4) & $\begin{array}{l}\text { Material for accessible } \\
\text { for the second time (2) }\end{array}$ \\
\hline Perceptions of teaching style & Usage of resources offered (2) & Frustrating for A Level students (4) \\
\hline Allows flexibility in engagement (1) & Insufficient explanation if unprepared (2) \\
\hline Allows more time for explanation (1) & $\begin{array}{l}\text { Negative impact on non-traditional } \\
\text { students (2) }\end{array}$ \\
\hline Builds confidence for \\
\hline traditional students (2)
\end{tabular}

\section{Conclusions}

Tailored blended learning is an integrated approach to the facilitation of active learning that utilises the affordance of virtual learning environments and audience response technologies. We are confident it provides a flexible and scalable pedagogy with the potential to spread widely through leveraging the resources being developed during the Covid-19 pandemic. However, this study illustrates that there remain considerable challenges sustaining the engagement of a diverse cohort of undergraduates over a 12-week course. We cannot present the drop-off in virtual learning environment and lecture theatre interactivity as anything other than disappointing. Our preliminary observations from the 20/21 academic year, where this blended approach was largely maintained but the synchronous teaching has been moved online, is that the patterns of engagement are very similar. The authors have sought to rely upon the principles of formative assessment and informed constructive engagement with limited success. It would be interesting to compare the impact of a programme in which the weekly tests were summative or online engagement was compulsory. The qualitative results revealed very mixed opinions of the 'flipped' teaching approach amongst students. There are many factors that affect student's decision and ability to engage and that whilst prior knowledge is one, so too are the student's attitude towards the resources, personal circumstances and use of external resources also contribute.

The students in this study provided a number of very encouraging comments during the course of our qualitative evaluation. Some of the students expressed their desire to see additional resources, seemingly contradicting the picture of declining engagement over the course of the semester. Globally academics are making decisions about how to conduct blended learning during the pandemic crisis and what to retain in its aftermath, we advise judicious and realistic deployment of resources. Students are diverse, conflicted and strategic and will make complex and dynamic choices about their level of engagement.

\section{Supplementary Information}

Supplementary Information for this article is available at https://www.ingentaconnect.com/content/scs/chimia

\section{Acknowledgements}

The authors are grateful to the foundation year student cohorts on CHE-3004A, who provided their informed consent to participate in this study. SC and FS were undergraduate project students at the time of the study and acknowledge the support of the School of Chemistry for this study. We are grateful to Dr Charlie Williams for the advice and guidance regarding the ethics application and the qualitative methods. SC and FS would like to thank their peers Harriet Davies, Jonathan Eracleous and Connor Vintiner for co-coding the interview transcripts.

Received: November 16, 2020

[1] S. Dhawan, J. Educ. Technol. Syst. 2020, 49, 5, https://doi.org/10.1177/0047239520934018.

[2] A. A. Okaz, Procedia-Soc. Behav. Sci. 2015, 186, 600, https://doi.org/10.1016/j.sbspro.2015.04.086.

[3] What qualification levels mean. https://www.gov.uk/what-different-qualification-levels-mean/list-of-qualification-levels, accessed November 26, 2020.

[4] B. J. Allan, J. Found. Year Netw. 2018, 1, 11 .

[5] What University Course Should You Study? https://www.ucas.com/undergraduate/what-and-where-study/ucas-undergraduate-what-study, accessed January 8, 2019

[6] 'Foundation Years Explained', January 8, 2019, from https://www.brightknowledge.org/education/foundation-years-explained, accessed January 8 , 2019.

[7] G. K. Kinsella, C. Mahon, S. Lillis, Act. Learn. High. Educ. 2017, 18, 231, https://doi.org/10.1177/1469787417715205.

[8] S. R. Chipperfield, J. Furth. High. Educ. 2012, 36, 333 https://doi.org/10.1080/0309877X.2011.632817.

[9] C. Hockings, S. Cooke, M. Bowl, Teach. High. Educ. 2007, 12, 721, https://doi.org/10.1080/13562510701596323.

[10] G. M. Novak, E. T. Patterson, A. D. Gavrin, W. Christian, 'Just-in-TimeTeaching: Blending Active Learning with Web Technology', Prentice Hall, Upper Saddle River, NJ, 1999.

[11] H. Frick, J. Birt, J. Waters, Account. Financ. 2020, 60, 271, https://doi.org/10.1111/acfi.12318.

[12] M. Moravec, A. Williams, N. Aguilar-Roca, D. K. O'Dowd, CBE Life Sci. Educ. 2010, 9, 473, https://doi.org/10.1187/cbe.10-04-0063.

[13] M. K. Seery, Chem. Educ. Res. Pract. 2015, 16, 758, https://doi.org/10.1039/c5rp00136f.

[14] J. F. Eichler, J. Peeples, Chem. Educ. Res. Pract. 2016, 17, 197, https://doi.org/10.1039/c5rp00159e.

[15] D. Read, S. Lancaster, Educ. Chem. 2012, 49, 13

[16] S. Lancaster, Educ. Chem. 2014, 51, 18. 
[17] M. Sarsfield, J. Conway, Res. Learn. Technol. 2018, 26, 1, https://doi.org/10.25304/rlt.v26.2087.

[18] We choose to use the expression 'lecture recording' and not 'lecture capture' very deliberately. Technology can record what happens in the lecture theatre. It cannot capture the learning experience.

[19] A. Roehl, S. L. Reddy, G. J. Shannon, J. Fam. Consum. Sci. 2013, 105, 44 https://doi.org/10.14307/jfcs105.2.12.

[20] R. A. Burnstein, L. M. Lederman, Phys. Teach. 2001, 39, 8, https://doi.org/10.1119/1.1343420.

[21] K. Struyven, F. Dochy, S. Janssens, Interact. Learn. Environ. 2012, 20 391, https://doi.org/10.1080/10494820.2010.500084.

[22] National Research Council, 'How People Learn: Brain, Mind, Experience, and School: Expanded Edition.', National Academies Press, Washington, D. C, 2000

[23] S. Freeman, S. L. Eddy, M. McDonough, M. K. Smith, N. Okoroafor, H. Jordt, M. P. Wenderoth, Proc. Natl. Acad. Sci. U. S. A. 2014, 111, 8410, https://doi.org/10.1073/pnas.1319030111.

[24] A. K. Wood, R. K. Galloway, C. Sinclair, J. Hardy, Teach. High. Educ. 2018, 23, 818, https://doi.org/10.1080/13562517.2017.1421630.

[25] G. M. Bodner, M. Orgill, 'Theoretical Frameworks for research in chemistry/science education', Prentice Hall, Upper Saddle River, NJ, 2006.

[26] J. L. Bishop, M. A. Verleger, ASEE Annu. Conf. Expo. Conf. Proc. 2013, https://doi.org/10.18260/1-2--22585.

[27] E. Mazur, R. C. Hilborn, Phys. Today 1997, 50, 68, https://doi.org/10.1063/1.881735.

[28] S. Lancaster, D. F. Cook, W. J. Massingberd-Mundy, 'Teaching Chemistry in Higher Education: A Festschrift in Honour of Professor Tina Overton', Creathach Press, UK, 2019.

[29] N. Lasry, E. Mazur, J. Watkins, Am. J. Phys. 2008, 76, 1066, https://doi.org/10.1119/1.2978182.

[30] J. A. Schell, A. C. Butler, Front. Educ. 2018, 3, 1, https://doi.org/10.3389/feduc.2018.00033.

[31] H. Coates, Qual. High. Educ. 2005, 11, 25, https://doi.org/10.1080/13538320500074915.

[32] L. S. Shulman, Chang. Mag. High. Learn. 2002, 34, 36, https://doi.org/10.1080/00091380209605567.

[33] S. L. Christenson, C. Wylie, A. L. Reschly, Handb. Res. Student Engagem 2012, 1, https://doi.org/10.1007/978-1-4614-2018-7.

[34] M.-T. Wang, J. Degol, Child Dev. Perspect. 2014, 8, 137, https://doi.org/10.1111/cdep.12073.

[35] N. Zepke, Teach. High. Educ. 2014, 19, 697, https://doi.org/10.1080/13562517.2014.901956.
[36] C. R. Henrie, L. R. Halverson, C. R. Graham, 'Measuring student engagement in technology-mediated learning: A review', 2015 , https://doi.org/10.1016/j.compedu.2015.09.005.

[37] J. A. Fredricks, P. C. Blumenfeld, A. H. Paris, Rev. Educ. Res. 2004, 74, 59, https://doi.org/10.3102/00346543074001059.

[38] O. N. Sunday, Journal?? 2013, 1, 1.

[39] K. Singh, M. Granville, S. Dika, J. Educ. Res. 2002, 95, 323 , https://doi.org/10.1080/00220670209596607.

[40] B. J. Mandernach, E. Donnelli-Sallee, A. Dailey-Hebert, 'Promoting Student Engagement', Vol. 1: 'Programs, Techniques and Opportunities' 2011, pp 277.

[41] P. Trowler, V. Trowler, High. Educ. 2010, 1.

[42] K. L. Krause, H. Coates, Assess. Eval. High. Educ. 2008, 33, 493, https://doi.org/10.1080/02602930701698892.

[43] M. Yorke, 'Measuring student engagement in UK higher education A personal view - HEA Surveys Conference Understanding and enhancing the student experience.', 2017.

[44] E. R. Kahu, Stud. High. Educ. 2013, 38, 758, https://doi.org/10.1080/03075079.2011.598505.

[45] N. Zepkea, L. Leach, P. Butler, Stud. High. Educ. 2011, 36, 227, https://doi.org/10.1080/03075070903545074.

[46] We have developed a coding system that allows the quantification of activity in the lecture theatre. Those who regard their lecture style as already highly interactive, might be surprised to learn that in our fully flipped chemistry class practising peer instruction, $50 \%$ of the time is still the lecturer framing the question and explaining its answer.

[47] Information was not available for lectures in weeks 2 and 3 of academic year 2018-19

[48] D. Bye, D. Pushkar, M. Conway, Adult Educ. Q. 2007, 57, 141 , https://doi.org/10.1177/0741713606294235.

[49] R. Ellis, R. Allan, J. Furth. High. Educ. 2010, 34, 23, https://doi.org/10.1080/03098770903477078.

\section{License and Terms}

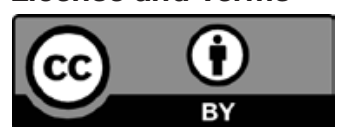

This is an Open Access article under the terms of the Creative Commons Attribution License CC BY 4.0. The material may not be used for commercial purposes.

The license is subject to the CHIMIA terms and conditions: (http:// chimia.ch/component/sppagebuilder/?view=page \&id=12).

The definitive version of this article is the electronic one that can be found at https://doi.org/10.2533/chimia.2021.18 